\title{
A system of air recirculation and antibacterial surface treatment in a surgical ward
}

\author{
G. A. J. AYLIFFE AND M. A. BEARD ${ }^{1}$ \\ with the technical assistance of \\ J. FILBEY
}

From the Department of Bacteriology, Postgraduate Medical School of London, Hammersmith

SYNOPSIS A system of surface treatment with an antibacterial agent and air recirculation throughin treated filters was set up in a 15-bedded surgical ward, using an adjacent 10-bedded ward as a control.

Nasal, wound, and urinary cross-infection was studied in both wards for over one year.

Total bacterial counts and counts of Staphylococcus pyogenes were made from settle plates and blanket sweep plates.

After the installation of the system aerial contamination in the test ward was reduced appreciably more than in the control ward. The number of blankets contaminated with Staph. pyogenes was similar in both wards. There was no significant difference in wound, nasal, or urinary cross-infectiono between the two wards.

The importance of the infected patient and probably the 'carrier' as the main source of hospital infection is well known. The route by which it is spread in surgical wards is still not clear, and in particular we have little knowledge of the degree to which spread may occur through aerial contamination. It was therefore decided to set up in a urological ward the system of bactericidal air conditioning described by Hudson, Sanger, and Sproul (1959).

The main objects of the test were to assess the effects of this system on the numbers of airborne bacteria and on staphylococcal cross-infection. The system consists of two main parts. The first involves the treatment of all surfaces in the ward, including blankets and curtains, with an antibacterial agent. The second part consists of air recirculation through filters impregnated with the same antibacterial agent.

In the investigation described here two adjacent male surgical wards were used, both of which had a predominance of genito-urinary patients (Fig. 1). The system was set up in one of the two wards, which had 15 beds, and the other, a 10-bedded ward, was kept as a control. The side rooms of the test ward consisted of a bathroom, two patients' W.C.s, a staff W.C., a sluice room, sterilizing room, instru-

Received for publication 5 September 1961.

${ }^{3}$ Working with a grant from the Medical Research Council. ment room, and kitchen. The last four served both $\stackrel{2}{\stackrel{2}{2}}$ test and control wards. The side rooms of the control $\overrightarrow{\vec{A}}$ ward consisted of a bathroom, patients' W.C., $Э$ sister's room, and a one-bed isolation room. Since $\bar{P}$ the beginning of the test the type of patient has been kept as comparable as possible, and the same nursing and domestic staff have been employed in? both wards.

TESTS OF PERMACHEM IN VITRO

The antibacterial agent used in this study is known as윽 Permachem and consists of a number of formulae, the main active ingredients being tributyl tin oxide and을 quaternary ammonium compounds.

A comparison was made of the antibacterial action of $\widetilde{N}$ Permachem 51 (T.B.T.O. 4.07\%), a quaternary am- $N$ monium compound (Arquad 16-50), and $\mathrm{N}$-alkyl tri-요 methylene diamine. The results of tube and blanket $\omega$ experiments showed no marked difference between Arquad 16-50 and Permachem. Using 1 in 200 dilutionso in broth, both were bactericidal against Staph. pyogenes $\frac{\bar{D}}{\varnothing}$ but less so against Gram-negative bacilli and ineffective $\stackrel{\mathcal{S}}{-}$ against the strains of $P s$. pyocyanea tested. The addition of $\mathrm{N}$-alkyl trimethylene diamine 1 in 10,000 to either $\bar{O}$ Permachem or Arquad 16-50 considerably increased $\overrightarrow{\mathbb{D}}$ their activity against this organism. Subcultures were $\frac{\mathcal{P}}{\bar{D}}$ made on to egg-tween agar medium (Morris and Darlow, $₫$ 1959), which was a suitable neutralizing medium for Arquad 16-50 and the best available for Permachem. 


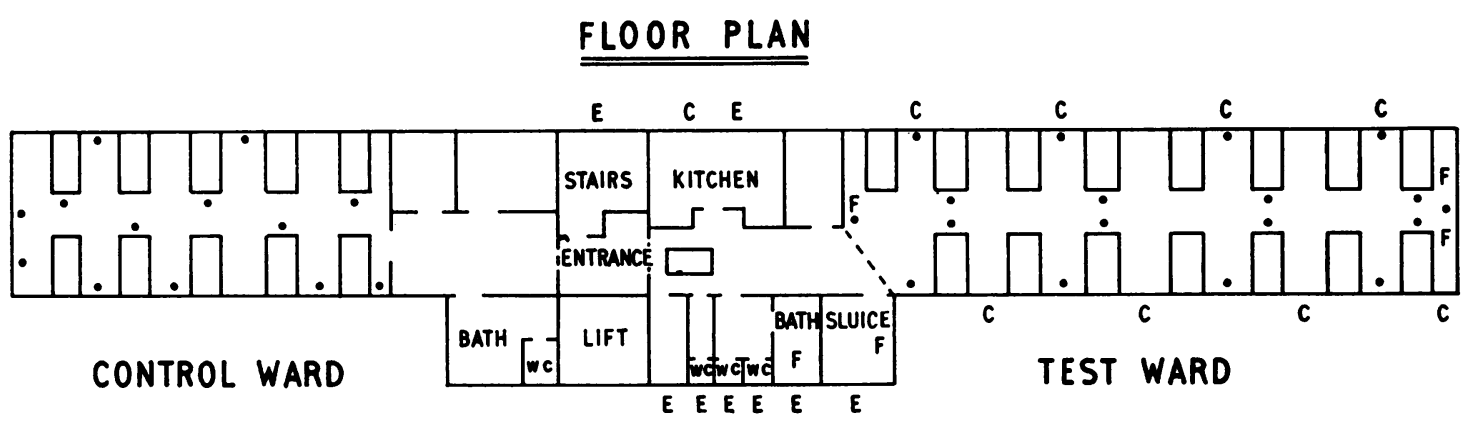

- Settle Plate ; $E=$ Exhaust Fan ; $C=$ Window Recirculator; $F=$ Floor Recirculator

FIG. 1. Floor plan of control and test wards.

GENERAL SCHEME OF WARD STUDY

The test ward was thoroughly cleaned and all surfaces, such as walls, ceilings, cupboards, and windows, were treated with one of the Permachem formulae. Wash basins, W.C.s, beds, baths, and sinks were cleaned and sprayed, and the ward linen treated with Permachem. The control ward was cleaned at the same time and sprayed with cetrimide, and the blankets and curtains were treated with Arquad 16-50, a procedure already in use throughout the hospital.

The test ward was equipped with 12 recirculators (Fig. 1), eight of which were fitted to windows and four were placed on the floor, two at each end of the ward. In addition a recirculator was placed in both the bathroom and the sluice room. During the first eight months of the test, each recirculated $500 \mathrm{cu}$. ft. per minute and the total ward air every five minutes, giving a complete change of ward air every 30 minutes.

The window units drew in $25 \%$ of air from outside, and this amount could be varied depending on the ward temperature, which was maintained at about 65 to $67^{\circ} \mathrm{F}$. Each recirculator was fitted with two cellulose filters impregnated with Permachem. It is claimed that these trap from 60 to $90 \%$ and kill $99 \%$ of the trapped bacteria in the air passing through the filter.

A plastic screen and curtain separated the patient area from the side rooms, and a positive pressure was maintained in the patient area, thereby preventing contaminated air from entering the ward. Exhaust fans were placed in the sluice room, bathroom, W.C.s, sterilizing room, kitchen, and over the stairway at each end of the ward. This arrangement ensured that contaminated air would flow away from the patients, and out through the exhaust fans in the side rooms and outside the ward. An input fan was also inserted in the kitchen and adjusted to maintain a slight positive pressure, as contamination from the patient area was obviously undesirable.

One of the two filters in each recirculator was changed weekly by the engineering department.

There were a number of occasions when the recirculators were not working at maximum efficiency. This was due mainly to electrical faults, and sometimes to a failure to change filters at the correct times. The electrical faults were due to a failure in the alternator which converted the voltage from American voltage to English. The alternator was destroyed by floods in August and has been replaced by a new British alternator which has worked satisfactorily. At this time each recirculator was changed to recirculate at $700 \mathrm{cu}$. ft. per minute and the total ward air every two or three minutes.

The laundry used Permachem in the final rinse after washing blankets, woollen sheets, curtains, doctors' coats, and initially patients' pyjamas and nurses' uniforms. Nurses and domestic staff were given a bottle containing Permachem for their personal washing, but this, as well as rinsing their uniforms and patients' pyjamas in the laundry, was stopped because of the development of rashes. The treated laundry was marked with a green tab and kept in separate clearly marked bags. This was essential as the same sluice room was used for the test and control wards.

A large rubber mat was placed inside the door of the test ward and moistened with Permachem. Everyone entering the ward walked over this mat, and in addition trolleys and equipment from other parts of the hospital were sprayed with an aerosol.

Treated white coats were kept on coat hangers near the door. All doctors and other hospital staff changed to one of these on entering the ward; also shoes and trouser cuffs were sprayed. These measures were designed to reduce contamination from other parts of the hospital. No restrictions were placed on visitors as it was thought unlikely that they would bring into the ward any hospital strains of organisms.

Floors were cleaned daily by mopping with water containing Permachem. Sinks, W.C.s and baths were sprayed daily. The rubber mat in the doorway was moistened daily, and more than once. if necessary. Permachem was also incorporated in furniture polish, floor polish, and window wax, and the vacuum cleaner bags and filter were treated.

Urine bottles were immersed in a solution of Permachem, and a small quantity was left in the bottle before returning it to the patient.

A bowl of water containing Permachem was kept on a 
movable stand in the ward for doctors and nurses to rinse their hands after attending patients. Paper towels were also introduced into both test and control wards.

Dirty dressings, after removal from the patient, and any area of contamination in the ward were sprayed. Food, crockery, and cutlery were not sprayed or treated in any way with Permachem.

Apart from the initial treatment, as few new procedures as possible were introduced in the control ward, although inevitably some of the new measures, such as the use of paper towels and treatment of urine bottles, probably had effects in both wards. The exhaust fans in the test ward, and particularly over the stairway, almost certainly removed air from the control ward as well as from the test ward. This was particularly obvious in the later stages of the experiment when the doors between the wards were more often left open.

The wards were resprayed respectively with Permachem or Cetrimide after eight months.

\section{WARD INVESTIGATIONS}

AIR STUDIES Air contamination was studied by means of settle plates containing serum phenolphthalein phosphate nutrient agar (Barber and Kuper, 1951).

Settle plates were used in this experiment rather than a slit sampler to determine the degree of air contamination for two main reasons. The first was that counts could be obtained from all areas in the wards over the same time period, and secondly it was thought that these counts would be more representative of organisms likely to fall on the surface of an exposed wound.

The plates were exposed and placed for one hour on bedtables and lockers in the patient area and also in earlier tests on sinks and in the side rooms of both wards. Seventeen plates were exposed in the patient area of the test ward and 12 in the control ward.

Before the system was installed, tests were carried out three times a week for four weeks. More extensive studies were made for three days before and three days after the installation of the system. These were performed twice daily from 10.30 to 11.30 in the morning and from 3.30 to 4.30 in the afternoon. Since then, tests have been carried out once or twice weekly for most of the year. This weekly test included the afternoon during which activity in both wards was usually at its highest level.

Total colony counts were made on all plates after 20 to 24 hours' incubation and Staph. pyogenes enumerated.
BLANKETS Pieces of blanket were cut into 2 foot squares $\stackrel{\frac{0}{7}}{\frac{1}{2}}$ and treated with Permachem or Arquad by the usual 음 laundry methods. One square of each of these and an untreated square were sewn to a ward blanket. Three of $\overrightarrow{\bar{S}}$ these blankets were placed on patients' beds and covered $\bar{O}$ with a bed-cover in the usual way. Press plates were made $\bar{\sigma}$ with serum phosphate phenolphthalein plates and egg- $\overline{\bar{C}}$ tween agar plates after two days and at intervals up to $\vec{\Phi}$ 19 days.

In addition sweep plates (Blowers and Wallace, 1955) ڤ were made from 10 blankets once a week in control and $\overrightarrow{0}$ test wards. A similar area from the top blanket of each bed was used.

NASAL SWABS These were taken from all patients once a week and plated on phenolphthalein phosphate agar.

WOUND SWABS These were collected from patients with 'open' wounds twice a week, and urine samples were collected from genito-urinary patients two to three times a week. Wound swabs and urines were plated on blood agar and McConkey plates and the organisms isolated were recorded.

The antibiotic sensitivity pattern of all strains of $\stackrel{\text { शे }}{<}$ Staph. pyogenes isolated was determined by using ditch $\vec{\theta}$ plates, and selected colonies were phage typed by the method of Williams and Rippon (1952).

\section{RESULTS}

BACTERIAL CONTENT OF AIR The average colony

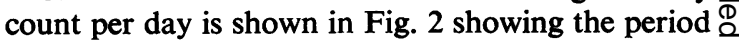
before installation and the first three months after $\overrightarrow{\overrightarrow{0}}$ installation. The results are based on the plates exposed in the patient areas of both wards and $\vec{P}$ represent the average colony count per plate per day. This shows that the counts in the test ward remained consistently low except on the two occasions when? the recirculators were subsequently found to be $\frac{0}{3}$ working incorrectly. These results were confirmed by later experiments when the recirculators were not working over a six-week period, and when on re-

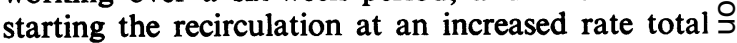
counts again fell to a lower level than that obtained $\frac{D}{O}$ previously in the test ward. The counts in the control ward also fell on this occasion, further suggesting $\mathrm{N}$ that the air system affected both wards.

TABLE I

$\begin{array}{ccll}\text { SETTLE PLATE } & \text { COUNTS } & \\ \begin{array}{l}\text { Number of } \\ \text { Plates }\end{array} & \begin{array}{l}\text { Average } \\ \text { Colony Count } \\ \text { per Plate }\end{array} & \begin{array}{l}\text { Percentage of } \\ \text { Plates showing } \\ \text { Staph. pyogenes }\end{array} & \begin{array}{l}\text { Percentage of } \\ \text { Plates showing } \\ \text { Multiple Resistant } \\ \text { Staph. pyogenes }\end{array}\end{array}$

Test Ward

Before installation of system (27 Oct. 1959 to 1 Dec. 1959)

After installation of system (1 Dec. 1959 to 28 April 1960)

\section{7}

544

Control Ward

Before installation of system (27 Oct. 1959 to 1 Dec. 1959)

After installation of system (1 Dec. 1959 to 28 April 1960)
163
384
190

45

103

100

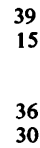

36
30
23

5

20
6 


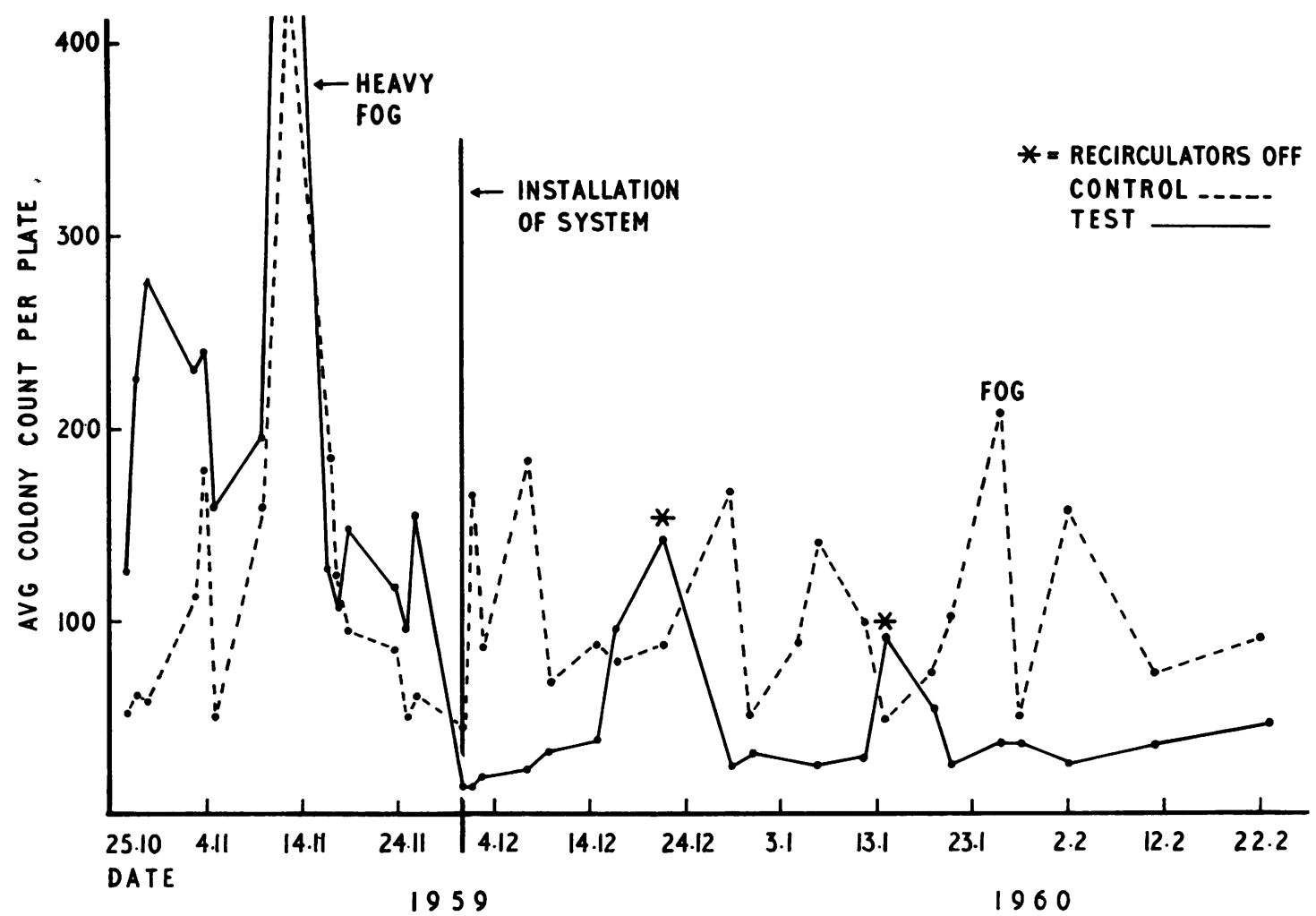

FIG. 2. Average colony count in control and test wards.

Table I shows a significant reduction in the number of plates showing Staph. pyogenes in the test ward, and a lesser, not statistically significant, fall in the control ward. There is a significant reduction in both wards in the number of plates showing multiresistant Staph. pyogenes. An increase in air contamination, including Staph. pyogenes, occurred during the period in which the circulators were switched off, with a corresponding fall on restarting the circulators.

BLANKETS The colony counts of the press plates from the squares of blankets sewn to ward blankets showed no appreciable difference between treated and untreated blankets. Mean counts from 14 samples were 72 colonies per plate for Permachem, 72 for Arquad, and 84 for untreated squares. Staph. pyogenes was isolated from both Permachemand Arquad-treated and untreated squares on the blanket of an infected patient on four occasions over a period of nine days in similar numbers.

The percentage of blankets contaminated with Staph. pyogenes was similar in both wards and depended mainly on the number of infected patients or nasal carriers.
Twenty-five per cent of 542 blankets were contaminated in the control ward and $21 \%$ of 852 blankets in the test ward. Staph. pyogenes was isolated from only $1.2 \%$ of blankets in the control ward and $0.7 \%$ in the test ward from the beds of uninfected patients or patients who were not nasal carriers.

Before the wards were resprayed it was found that many of the blankets in both wards were contaminated with Ps. pyocyanea. Investigation showed that these blankets were contaminated before leaving the laundry. Ps. pyocyanea was subsequently isolated from the blanket wash, rinse water, and Permachem rinse. Thereafter the blankets were heated according to the recommendation of the British Launderers' Research Association (British Launderers' Research Association and International Wool Secretariat, 1959) but were still rinsed in Permachem or Arquad. No further Ps. pyocyanea were isolated from clean blankets.

NOSES AND WOUNDS Table II shows the number of noses and wounds acquiring Staph. pyogenes during the year. The total nose figure refers to the number of patients from whom at least two swabs were 
TABLE II

WOUNDS AND NOSES ACQUIRING STAPH. PYOGENES BETWEEN 1 DECEMBER 1959 AND 1 DECEMBER 1960

\begin{tabular}{lll}
$\begin{array}{l}\text { Total Noses } \\
\text { or Wounds }\end{array}$ & $\begin{array}{l}\text { Sensitive or } \\
\text { Penicillin- } \\
\text { resistant } \text { Staph. } \\
\text { pyogenes }\end{array}$ & $\begin{array}{l}\text { Multiple } \\
\text { Resistant } \\
\text { Staph. pyogenes }\end{array}$ \\
\hline
\end{tabular}

\begin{tabular}{lrrr}
\hline Test Ward & & & \\
Noses & 98 & 13 & 10 \\
Wounds & 54 & 8 & 12 \\
& & & \\
Control Ward & 68 & 12 & 8 \\
Noses & 51 & 11 & 10 \\
Wounds & & &
\end{tabular}

taken, the first of which was negative. The total wound figure represents the number of patients with wounds which were liable to become infected in the ward. It does not include undrained clean-stitched wounds, definite theatre infections, or wounds already infected on the patients' admission. There is no significant difference between the two wards in the number of noses or wounds acquiring Staph. pyogenes.

URINES Cross-infection occurred in both test and control wards after installation of the Permachem system. There was no significant difference in the two wards in the numbers of patients acquiring Staph. pyogenes, Proteus, and Ps. pyocyanea in the urine.

\section{DISCUSSION}

The settle plate counts before and after the installation of the Permachem system were much higher in the test ward than similar counts obtained by Hudson et al. (1959) in their wards. The test ward was an open ward containing 15 rather closely spaced beds, whereas the Delafield wards studied by Hudson were separate rooms of four to six beds. The results before the installation of the system were also higher in the test than in the control ward. This was probably due to the larger number of patients in the test ward. Nevertheless, following the introduction of the system the bacterial content of the air remained consistently lower in the test ward, confirming the results of Hudson.

The reduction in the number of plates showing Staph. pyogenes in the test ward suggests that aerial dissemination of this organism had also been reduced and there was a reduction in multiple resistant Staph. pyogenes in both wards with corresponding increases when the recirculators were off. These results indicate that the control ward was probably affected by improvements in the test ward.

The experiments with treated and untreated squares attached to ward blankets confirm the results $\frac{0}{5}$ of Rubbo, Stratford, and Dixson (1960) that $\frac{0}{-}$ although disinfectants are useful for initial sterilizing $\vec{\Rightarrow}$ of blankets they have little effect in preventing them $\stackrel{5}{+}$ becoming contaminated in the ward. This is further confirmed by the results of ward blanket sampling $\frac{\overline{0}}{\bar{N}}$ which shows that Permachem is not superior to the quaternary ammonium compounds in preventing $\triangle$ contamination with Staph. pyogenes on the patients' beds.

Neither quaternary ammonium compounds alone nor the Permachem formula used in the experiment $\vec{\omega}$ are suitable for sterilizing hospital blankets because they are ineffective against $P s$. pyocyanea. It may? happen, as it did at one stage in our experiments, $\vec{G}$ that Ps. pyocyanea not only survives the laundry $\omega$ process but contaminates the whole batch of blankets. i

In spite of the reduction in aerial contamination $\vec{N}$ in the test ward there was no significant difference $ᄋ$ between the two wards in wound and nasal cross- infection with Staph. pyogenes. Better results might have been obtained with improvements in the ward recirculating system but it is doubtful whether any $\vec{\theta}$ system could prevent cross-infection in a busy ? general ward to which infected patients are admitted. Preliminary experiments in a small one-bedded side ward equipped with two recirculators showed much lower settle plate counts than were obtained in the test ward. The system, therefore, might well be $\mathbb{D}$ considered as a method of supplying clean air to small dressing-rooms, isolation rooms, burns units, and operating theatres.

We wish to thank Dr. Mary Barber, under whose direction this work was carried out, Professor Shackman for his cooperation and the opportunity for studying his? patients, Sister Rackham and the nursing staff for their work and enthusiasm, also the many departments involved in the setting up and maintenance of the system, and Miss Margaret Sheppard for technical assistance.

We also wish to thank Simmonds Aerocessories Ltd., 을 Treforest, for supplying recirculators and treated filters, Genatosan Ltd., Loughborough, for supplying the Permachem formulae, and Armour Hess Chemicals Ltd., for supplying $\mathrm{N}$-alkyl trimethylene diamine. O

\section{REFERENCES}

Barber, Mary, and Kuper, S. W. A. (1951). J. Path. Bact., 63, 65. Blowers, R., and Wallace, K. R. (1955). Lancet, 1, 1250.

British Launderers' Research Association and International Woolco Secretariat (1959). High Temperature Laundering of Woollen $\frac{\bar{C}}{\Phi}$ Hospital Blankets. London.

Hudson, P. B., Sanger, G., and Sproul, E. E. (1959). J. Amer. med. $\stackrel{\mathscr{S}}{+}$ Ass., 169, 1549.

Morris, E. J., and Darlow, H. M. (1959). J. appl. Bact., 22, 64.

Rubbo, S. D., Stratford, B. C., and Dixson, S. (1960). Med. J. Aust.,

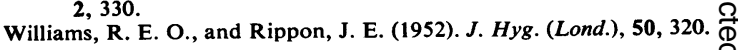

